\title{
Leaf Photosynthesis in Nitrogen-starved 'Western' Pecan Is Lower on Fruiting Shoots than Non-fruiting Shoots during Kernel Fill
}

\author{
Richard J. Heerema ${ }^{1}$ \\ Department of Plant and Environmental Sciences, New Mexico State University, MSC 3AE Box \\ 30003, Las Cruces, NM 88003
}

\author{
Dawn VanLeeuwen \\ Economics, Applied Statistics, and International Business Department, New Mexico State University, \\ MSC 3CQ Box 30001, Las Cruces, NM 88003 \\ Rolston St. Hilaire \\ Department of Plant and Environmental Sciences, New Mexico State University, MSC 3Q Box 30003, \\ Las Cruces, NM 88003 \\ Vince P. Gutschick and Bethany Cook \\ Department of Biology, New Mexico State University, MSC 3AF Box 30001, Las Cruces, NM 88003
}

\begin{abstract}
AdDitional INDEX words. carbon assimilation, Carya illinoinensis, gas exchange, leaf senescence, nitrogen use efficiency, nutrient deficiency

Abstract. Photosynthetic function in nut trees is closely related to nitrogen ( $N$ ) nutrition because much of tree $\mathbf{N}$ is held within the leaf photosynthetic apparatus, but growing fruit and seeds also represent strong $\mathbf{N}$ sinks. When soil $\mathrm{N}$ availability is low, nut trees remobilize and translocate $\mathbf{N}$ from leaves to help satisfy $\mathbf{N}$ demand of developing fruit. Our objective was to describe shoot-level impacts of pecan [Carya illinoinensis (Wangenh.) K. Koch.] fruiting on leaf $\mathrm{N}$ and photosynthesis $\left(P_{n}\right)$ during kernel fill under a range of tree $N$ statuses. Our study was conducted in a mature 'Western' pecan orchard near Las Cruces, NM. In 2009, 15 trees showing a range of $N$ deficiency symptom severity were grouped according to leaf SPAD into low, medium, and high $\mathrm{N}$ status categories. Differential $\mathrm{N}$ fertilizer rates were applied to the soil around high and medium $N$ trees to accentuate differences in $N$ status among the three categories. Light-saturated leaf $P_{n}$ was measured on fruiting and non-fruiting shoots during kernel fill in 2009 and 2010. After measurement of $P_{n}$, the leaflet and its leaflet pair partner were collected, dried, and analyzed for tissue $N$. Leaf $\mathbf{N}$ concentration was significantly lower on fruiting shoots than non-fruiting shoots on all three sampling dates. The tree $\mathbf{N}$ status main effect was also significant, whereas the two-way interaction of shoot fruiting status and tree $\mathbf{N}$ status was not. Photosynthesis of leaves on fruiting shoots was significantly lower than that of non-fruiting shoots on all sampling dates. These data suggest that $N$ demand by the growing kernel reduced $N$ in leaves on the same shoot. Consequently, $P_{n}$ of those leaves was reduced. The effect of tree $N$ status and shoot fruiting status was best summarized with an additive model where there is a larger relative reduction in leaf $N$ and $P_{n}$ for fruiting shoots on trees with low $\mathbf{N}$ status.
\end{abstract}

The $\mathrm{N}$ in mature pecan fruit, including the involucre (shuck), shell, and kernel, accounts for less than $5 \%$ of total $\mathrm{N}$ in the whole tree (Acuña-Maldonado et al., 2003; Kraimer et al., 2001). However, ripe pecan kernels are protein-rich (Singanusong et al., 2003; Wood and Reilly, 1984) and have N concentration of $1.5 \%$ to $2.0 \%$ (Hammar and Hunter, 1946; Lewis and Hunter, 1944; Thor and Smith, 1935). Pecan fruit therefore constitute sizeable $\mathrm{N}$ sinks at the shoot level during the period of rapid kernel growth in the 8 weeks before harvest (Hammar and Hunter, 1946;

Received for publication 4 Oct. 2013. Accepted for publication 12 Feb. 2014. This study was made possible by New Mexico State University Agricultural Experiment Station and Hatch funds.

We thank Midray Clark for the use of his pecan orchard and William Boecklen for assistance with the tissue nitrogen analyses. We are grateful to Malik Ghazi Al-Ajlouni, Yahia Othman, Lauren Radosevich, Joshua Sherman, and Heather Coley for their help with processing samples and collecting data in the field. We thank Mark Uchanski, Kevin Lombard, Marisa Potter, and Josh Sherman for their critical reviews of this manuscript.

${ }^{1}$ Corresponding author. E-mail: rjheerem@nmsu.edu.
Herrera, 1990). For example, Hammar and Hunter (1946) showed that total $\mathrm{N}$ content in 'Moore' pecan nuts (involucre, shell, and kernel) increased from $41.3 \mathrm{mg} / \mathrm{nut}$ in late August to $70.0 \mathrm{mg} / \mathrm{nut}$ in late October, which could be completely accounted for by kernel $\mathrm{N}$ accumulation (involucre $\mathrm{N}$ content actually declined during that same period).

Fruiting in pecan and other nut trees is associated with shootlevel reductions in leaf $\mathrm{N}$ concentration and leaf area-based $\mathrm{N}$ content (Diver et al., 1984; Heerema et al., 2009; Klein et al., 1991), which suggests that growing fruit and seeds can draw on $\mathrm{N}$ remobilized from nearby leaves to help meet $\mathrm{N}$ demands, especially when current-season tree $\mathrm{N}$ uptake is low. Developing fruit and seeds in annual plants initiate a similar well-described process in which leaf nutrients, and $\mathrm{N}$ in particular, are remobilized and translocated out of leaves to help meet reproductive mineral nutrient requirements elsewhere in the plant (Sesay and Shibles, 1980; Simpson et al., 1983).

Leaf $\mathrm{N}$ remobilization is associated with reductions in leaf photosynthetic capacity (e.g., Aguera et al., 2010), which is not 
surprising because as much as $75 \%$ of the $\mathrm{N}$ in $\mathrm{C}_{3}$ plants' leaves is held in the photosynthetic apparatus (Evans, 1989; Evans and Terashima, 1987). The Calvin cycle enzyme, Rubisco (ribulose 1,5 bisphosphate carboxylase/oxygenase), holds the largest portion (15\% to 35\%) of leaf N (Barker and Bryson, 2007; Evans, 1989). In addition to its relationship to leaf Rubisco content, N supply impacts Rubisco activity, leaf chlorophyll content, thylakoid protein activity, and electron transport activity (Evans and Terashima, 1987; Kozlowski and Pallardy, 1997; Natr, 1975).

The objective of our study was to characterize shoot-level impacts of fruiting on leaf $\mathrm{N}$ and $\mathrm{P}_{\mathrm{n}}$ during the kernel fill stage for pecan trees with differing $\mathrm{N}$ status. If pecan fruit during kernel fill draw on $\mathrm{N}$ in leaves of the same shoot, we hypothesized that 1) the negative impact of fruiting at the shoot level on leaf $\mathrm{N}$ content would be greatest for $\mathrm{N}$-deficient pecan trees where soil $\mathrm{N}$ uptake to replace remobilized leaf $\mathrm{N}$ is low; and 2) increased differential leaf $\mathrm{N}$ content between fruiting and nonfruiting shoots for $\mathrm{N}$-deficient pecan trees will translate into decreased photosynthetic capacity of leaves on fruiting shoots compared with non-fruiting shoots. Our approach was to focus on fruiting impacts within individual shoots rather than evaluating impacts of whole-tree cropload or carbohydrate status.

\section{Materials and Methods}

Study SITE. This study was conducted in a mature (greater than 20 years old) commercial, basin-flood irrigated pecan orchard located in the Mesilla Valley west of Las Cruces, NM (lat. $32^{\circ} 17^{\prime} 05^{\prime \prime} \mathrm{N}$, long. $106^{\circ} 50^{\prime} 10^{\prime \prime} \mathrm{W}$, elevation $1184 \mathrm{~m}$ ). The region is characterized by a freeze-free growing period of $\approx 212 \mathrm{~d}$ and average annual precipitation of $\approx 23 \mathrm{~cm}$. Soils in the study orchard are deep (greater than $200 \mathrm{~cm}$ to restrictive feature), well-drained Harkey loam (thermic Typic Torrifluvents, available water-holding capacity $\approx 24.4 \mathrm{~cm}$ ), Agua clay loam (thermic Typic Torrifluvents, available water-holding capacity $\approx 16.5 \mathrm{~cm}$ ), and Brazito Very Fine Sandy Loam (thermic Typic Torripsamments, available water-holding capacity $\approx 13.0 \mathrm{~cm}$ ) (U.S. Department of Agriculture, 2013). Soils in the orchard are alkaline, ranging in $\mathrm{pH}$ from 7.4 to 8.4.

The cultivar used in the study was Western (synonym Western Schley). The rootstock cultivar was unknown but was likely open-pollinated seedling Riverside, the most widely used rootstock in area orchards of that age. The orchard contained randomly placed 'Ideal' (synonym 'Bradley') pollenizer trees. Trees in the orchard were visually estimated to be 10 to $11 \mathrm{~m}$ tall and were planted to an offset rectangle pattern with trees spaced $7.6 \mathrm{~m}$ between rows and $15.2 \mathrm{~m}$ within rows; therefore, tree planting density was 86 trees per hectare. Tree rows were oriented in about the southeast-northwest direction.

Except for application of $\mathrm{N}$ fertilizers, the commercial producer directed all management of the trees in the study site during the experiment. The orchard was irrigated every $\approx 14 \mathrm{~d}$ from April through October. Zinc, manganese (Mn), and iron (Fe) fertilizers were foliarly applied as needed in the spring using an airblast sprayer. Arthropod pest control was unnecessary during the study and orchard floor weeds were controlled as needed using a combination of cultivation and post-emergent herbicide application.

TREe SELECTION AND NITROGEN FERTILIZER APPLICATION. Some aspects of orchard management, particularly fertilizer application, had been erratic during 2007 and 2008 because of a transition in orchard ownership. It was noted in 2008 and Spring 2009 that some trees in this orchard exhibited mild to severe symptoms consistent with $\mathrm{N}$ deficiency-general leaf chlorosis and low vigor. Fifteen trees covering the range of apparent $\mathrm{N}$ deficiency symptom severity were selected 10 July 2009 for the study. Trees were selected based on the (visual) severity of the symptoms. Symptom severity was quantified using a portable chlorophyll meter (SPAD 502; Konica Minolta, Ramsey, NJ), which provides a measure of leaf greenness. For each tree, SPAD was measured midway between the midrib and margin of one middle leaflet on the middle leaf of three randomly selected non-fruiting shoots. Trees were divided into three tree $\mathrm{N}$ categories with the five trees exhibiting the most severe $\mathrm{N}$ deficiency symptoms (SPAD readings 26.4 to 31.4) classified as low $\mathrm{N}$, the five trees exhibiting moderate $\mathrm{N}$ deficiency symptom severity (SPAD 33.6 to 37.2 ) classified as medium $\mathrm{N}$, and the five trees exhibiting the least severe symptoms (39.7 to 46.7) classified as high N. Trees selected for the study were dispersed throughout one irrigation block of the orchard so that all were irrigated together.

Differential $\mathrm{N}$ fertilizer rates were broadcast on the orchard floor in a 4-m-diameter circle around the trunks of high and medium $\mathrm{N}$ trees. This was done to maintain or accentuate the initial differences in $\mathrm{N}$ nutrition among the three tree $\mathrm{N}$ status categories over the course of the study. In 2009, $5 \mathrm{~kg}$ urea fertilizer $(46 \mathrm{~N}-0 \mathrm{P}-0 \mathrm{~K})$ was applied around each high $\mathrm{N}$ tree and $2.5 \mathrm{~kg}$ urea was applied around each medium $\mathrm{N}$ tree on 19 Aug. In 2010, urea was broadcast around the trees as in 2009 but was split into three smaller applications made 15 Apr., 21 May, and 21 June. For each application in $2010,1.5$ and $0.7 \mathrm{~kg}$ urea was applied per tree for the high and medium $\mathrm{N}$ trees, respectively. During the study, no $\mathrm{N}$ fertilizers were applied to the low $\mathrm{N}$ symptom trees, except in 2010 when the landowner broadcast $168 \mathrm{~kg} \cdot \mathrm{ha}^{-1}(2 \mathrm{~kg} /$ tree $)$ monoammonium phosphate fertilizer $(11 \mathrm{~N}-22.7 \mathrm{P}-0 \mathrm{~K})$ over the floor of the entire orchard block, including under low, medium, and high $\mathrm{N}$ status trees.

Gas exchange measurements. Leaf gas exchange was measured on one fruiting and one non-fruiting shoot of each tree (for a total of 30 shoots each measurement date) during kernel fill stage using a portable $\mathrm{P}_{\mathrm{n}}$ system (LI-6400XT; LICOR, Lincoln, NE) equipped with a red/blue light-emitting diode light source (6400-02B; LI-COR). All fruiting shoots had two or three fruit in a cluster. Measurements were made only on fully sun-exposed middle leaflets of leaves in the middle of shoots 3 to $4 \mathrm{~m}$ above the ground on the southeast- or south-facing sides of each tree canopy. All gas exchange measurements were made between 0900 and $1300 \mathrm{HR}$ with irradiance (photosynthetically active radiation) held constant at $1700 \mu \mathrm{mol} \cdot \mathrm{m}^{-2} \cdot \mathrm{s}^{-1}$, which is a saturating light level for $\mathrm{P}_{\mathrm{n}}$ in pecan (Anderson, 1994). $\mathrm{CO}_{2}$ concentration was held constant in the chamber at $400 \mu \mathrm{L} \cdot \mathrm{L}^{-1}$. Leaf gas exchange was measured on 2 Oct. 2009, 1 Oct. 2010, and 5 Nov. 2010. Because 'Western' kernel fill continues through October in New Mexico, the early November photosynthesis measurement date was included in 2010 to ensure that we captured the full impact of local kernel $\mathrm{N}$ demand on leaves.

Water status of each tree was measured as midday stem water potential (i.e., bagged leaf water potential; Shackel et al., 1997) on each gas exchange measurement date. Starting at $\approx 1200 \mathrm{HR}$, two shaded leaves in the lower, interior portions of each tree canopy were placed in a sealed reflective bag for at least $30 \mathrm{~min}$ before leaf water potential was measured with a Scholander pressure chamber (PMS Instrument Co., Albany, 
OR). Average midday stem water potentials were $0.6,0.8$, and $0.5 \mathrm{MPa}$ for the experimental trees on 2 Oct. 2009, 1 Oct. 2010, and 5 Nov. 2010, respectively, which indicates that they were not significantly water-stressed on those dates (St. Hilaire and Othman, 2013).

Tissue SAMPLING AND NUTRIENT ANALYSES. The middle leaflet pair of the middle leaf of three fruiting and three non-fruiting shoots were sampled from each experimental tree on 10 July 2009 for $\mathrm{N}$ analysis. On 30 July 2010, leaflets were sampled for $\mathrm{N}$ analyses like in 2009, but only two fruiting and two nonfruiting shoots per tree were sampled. On that same date in 2010, additional leaflet tissue samples were collected from each experimental tree following the recommended leaf sampling protocol for commercial pecan producers in New Mexico (Heerema, 2013) to be analyzed for phosphorus (P), potassium $(\mathrm{K})$, calcium $(\mathrm{Ca})$, magnesium $(\mathrm{Mg})$, sulfur $(\mathrm{S})$, zinc $(\mathrm{Zn}), \mathrm{Fe}$, $\mathrm{Mn}$, copper $(\mathrm{Cu})$, and boron $(\mathrm{B})$ by inductively coupled plasma optical emission spectrometry at the New Mexico State University (NMSU) Soil, Water, and Agricultural Testing Laboratory (Gavlak et al., 1994; NMSU, 2013). After every leaf gas exchange measurement in 2009 and 2010, the leaflet measured and its leaflet pair partner were sampled for $\mathrm{N}$ analyses. Area of sampled leaflets was measured on a leaf area meter (LI-3100; LI-COR). Leaflets were washed with a mild detergent and rinsed with deionized water. Then leaflets were placed in a drying oven for $3 \mathrm{~d}$ at $60{ }^{\circ} \mathrm{C}$ before dry weights were measured. Leaf area and dry weight from each leaf sample allowed calculation of specific leaf weight (i.e., leaf dry weight per unit area), area-based leaf $\mathrm{N}$ content, and photosynthetic nitrogen use efficiency [PNUE (the ratio of $\mathrm{P}_{n}$ rate and areabased leaf $\mathrm{N}$ content)]. In 2010 one fruit was sampled from each experimental tree on 30 July, 1 Oct., and 5 Nov. for $\mathrm{N}$ analyses to track fruit $\mathrm{N}$ accumulation.

Dried pecan leaf tissues to be analyzed for $\mathrm{N}$ were placed in 1.5-mL centrifuge tubes with three 3.2-mm chrome-steel beads (BioSpec Products, Barlesville, OK) per tube and oscillated for 1.5 to 2 min with a modified reciprocating saw (Alexander et al., 2006). Approximately 0.6 to $0.7 \mathrm{mg}$ of powdered leaf tissue was loaded into foil capsules and stored in a desiccator. Two replicates were processed per leaf tissue sample. Whole fruit (shuck, shell, and kernel) samples to be analyzed for $\mathrm{N}$ were ground using a Wiley ${ }^{\circledR}$ Mini-Mill (Thomas Scientific, Swedesboro, NJ) and placed in 50-mL Falcon tubes. Approximately $10 \mathrm{mg}$ of ground fruit tissue per sample was loaded into foil capsules and stored in a desiccator. Three replicates were processed per fruit tissue sample.

Pecan leaf and fruit carbon and $\mathrm{N}$ analyses were performed at the Laboratory for Ecological Chemistry in Biology Department at NMSU. Leaf samples were combusted using an elemental analyzer (Costech Analytical Technologies, Valencia, CA) and introduced to a isotopic ratio mass spectrometer (Finnigan DeltaPlus XP; Thermo Scientific, Bremen, Germany) in continuous flow through a ConFlo III interface (Thermo Scientific). Fruit samples were combusted using an elemental analyzer (Flash 1112 Series; Thermo Finnigan, Devon, U.K.).

Statistical analyses. For each response variable and date, repeated-measures analysis of variance was conducted with tree $\mathrm{N}$ status (low, medium, high) as the treatment factor and shoot fruiting status (fruiting, non-fruiting) as the repeated factor. Either a compound symmetric or an unstructured covariance structure was fit to account for correlations between the two repeated measures. Information criteria, exploratory plots, residual analysis, and the Shapiro-Wilk test applied to studentized residuals were used to confirm adequacy of model assumptions including normality and to select between the two covariance structures. The outlier strategy (Ramsey and Schafer, 2002) was used to explore the impact of high-magnitude residuals (magnitudes greater than 2.5). Cases where re-analysis after removing outliers caused results to change from significant to insignificant are noted.

A mixed model regression of $\mathrm{P}_{n}$ on leaf $\mathrm{N}$ used began with an initial model that allowed fitting separate quadratic trends to each combination of date and fruiting status. Type I sequential hypotheses and sequential model fits were used to reduce the model, beginning with the highest order terms. A final model fitted a common trend to all dates and fruiting statuses but had different intercepts depending on additive effects of fruiting and date. The model incorporated random effects for tree, tree by date, and tree by fruiting effects to account for possible correlations among residuals from the same tree. A graphical summary of the fitted model adjusted data for the additive year effect to produce a simplified graph.

Analyses were obtained using SAS PROC MIXED software (Version 9.3; SAS Institute, Cary, NC). Significance was defined at $P \leq 0.05$.

\section{Results and Discussion}

At the beginning of our study in July 2009, mean leaf $\mathrm{N}$ concentrations were $1.6 \%, 1.7 \%$, and $2.2 \%$ of dry weight for the low, medium, and high $\mathrm{N}$ status trees, respectively. All 15 trees had leaf $\mathrm{N}$ concentration below the adequate range of $2.5 \%$ to $3.0 \%$ of dry weight (Heerema, 2013) at that time and average SPAD was significantly correlated with tissue $\mathrm{N}$ concentration of leaflets sampled from both non-fruiting $(r=0.9382 ; P<$ $0.0001)$ and fruiting $(r=0.89044 ; P<0.0001)$ shoots (data not presented). In July 2010 , mean leaf $\mathrm{N}$ concentrations were $1.5 \%$, $2.0 \%$, and $2.4 \%$ of dry weight for the low, medium, and high $\mathrm{N}$ status trees, respectively; two of the high N status trees had leaf $\mathrm{N}$ concentration in the $2.5 \%$ to $3.0 \%$ range in July 2010 (data not presented). Tissue nutrient analyses indicated mild $\mathrm{P}$ and $\mathrm{Mn}$ deficiencies in the study trees across all $\mathrm{N}$ status groupings in 2010 (mean leaf tissue $P$ and Mn concentrations were $0.11 \%$ and $47 \mu \mathrm{g} \cdot \mathrm{g}^{-1}$ by dry weight, respectively), but all other essential nutrients analyzed $(\mathrm{K}, \mathrm{S}, \mathrm{Ca}, \mathrm{Mg}, \mathrm{Zn}, \mathrm{Fe}, \mathrm{Cu}$, and $\mathrm{B}$ ) were within recommended concentration ranges for July-sampled leaflets (Heerema, 2013). Furthermore, there were no significant positive relationships between leaflet tissue $\mathrm{N}$ concentration and leaflet tissue concentration of any other essential nutrients (data not presented).

Fruit $\mathrm{N}$ concentration across tree $\mathrm{N}$ status was consistently $\approx 1 \% \mathrm{~N}$ by dry weight over the three sampling dates in 2010 (data not shown). However, because of increases in total fruit dry weight, the total fruit $\mathrm{N}$ content rose dramatically during the period from July to November. For the high $\mathrm{N}$ status trees, average $\mathrm{N}$ content increased by $79.6 \mathrm{mg} /$ fruit $(86.7 \%$ of final total fruit $\mathrm{N}$ ) between 30 July and 5 Nov. (data not shown). Similar patterns of pecan fruit development where $\mathrm{N}$ accumulation is concentrated in the later part of the growing season were shown by several other studies (Diver et al., 1984; Lewis and Hunter, 1944; Thor and Smith, 1935). In our study, measurements were made on shoots that had two or three fruit in a cluster; thus, total reproductive $\mathrm{N}$ accumulation for fruiting shoots on high $\mathrm{N}$ status trees in our study was at least $159 \mathrm{mg} / \mathrm{shoot} \mathrm{N}$ 
during the period of 30 July to 5 Nov. 2010. Because shoots that mature more than three fruit are common in 'Western' pecan trees in some years, the fruiting shoots in our study do not represent the upper extreme for fruit $\mathrm{N}$ demand at the shoot level.

For leaf $\mathrm{N}$ concentration (Table 1 ) and $\mathrm{N}$ content per square centimeter leaf area (data not presented) on all sampling dates during kernel fill stage in 2009 and 2010, both tree $\mathrm{N}$ status and shoot fruiting status main effects were significant. Across shoot fruiting status, the low $\mathrm{N}$ status trees had significantly lower leaf $\mathrm{N}$ concentration than the high $\mathrm{N}$ status on all three sampling dates and also had significantly lower leaf $\mathrm{N}$ concentration than the medium $\mathrm{N}$ status trees on both 2010 sampling dates (Fig. 1). Thus, differences in $\mathrm{N}$ nutrition among the tree $\mathrm{N}$ status groupings were consistent for both years of the experiment.

Leaf tissue from fruiting shoots during kernel fill had lower $\mathrm{N}$ than from non-fruiting shoots [main effect of shoot fruiting status pooled over tree $\mathrm{N}$ status (Table 1; Fig. 1)]. Across $\mathrm{N}$ status, in Oct. 2009, fruiting shoot leaf tissue $\mathrm{N}$ concentration was $0.13 \%$ points $\mathrm{N}$ lower than that of non-fruiting shoots $(1.26 \% \mathrm{~N}$ for fruiting vs. $1.39 \% \mathrm{~N}$ for non-fruiting). That same pattern also appeared on both 2010 measurement dates: in Oct. 2010 , fruiting shoot leaf $\mathrm{N}$ concentration was $0.41 \%$ points $\mathrm{N}$ lower than non-fruiting shoot leaf $\mathrm{N}$ concentration $(1.70 \% \mathrm{~N}$ for fruiting vs. $2.11 \% \mathrm{~N}$ for non-fruiting) and in Nov. 2010, the difference was $0.20 \%$ points $\mathrm{N}(1.27 \% \mathrm{~N}$ for fruiting vs. $1.47 \% \mathrm{~N}$ for non-fruiting; Fig. 1). The tree $\mathrm{N}$ status $\times$ branch fruiting status two-way interaction for leaf $\mathrm{N}$ concentration was not significant (Table 1). Thus, the additive model containing both fruiting and $\mathrm{N}$ status main effects implies that the absolute reduction in leaf $\mathrm{N}$ concentration was the same on low $\mathrm{N}$ and high $\mathrm{N}$ trees, but, because low $\mathrm{N}$ trees had a lower baseline value compared with high $\mathrm{N}$ trees, the relative reduction in leaf $\mathrm{N}$ concentration for fruiting shoots as compared with non-fruiting shoots was greater on low $\mathrm{N}$ trees than high $\mathrm{N}$ trees.

These $\mathrm{N}$ data suggest that fruit on $\mathrm{N}$-deficient pecan trees compete with the leaves on the same shoot for $\mathrm{N}$ transported to the shoot. This is in line with other studies on pecan that show localized impacts of fruiting on leaf N. In sixth leaf 'Chickasaw' pecan trees, Sparks (1977) found that leaves sampled in September from limbs de-fruited in July had higher $\mathrm{N}$ concentration (2.43\% vs. $2.19 \%)$ than leaves sampled from limbs where full cropload was retained. Diver et al. (1984) found in 'Western' pecan that leaf $\mathrm{N}$ concentration of fruiting shoots was higher than that of non-fruiting shoots for the first part of the growing season, but from late August (which coincided with the onset of rapid fruit $\mathrm{N}$ accumulation in their study) until their last measurement in mid-October, non-fruiting shoot leaf $\mathrm{N}$ concentration was higher than that of fruiting shoots.

Although trees in our study were N-deficient, it is likely that even pecan trees with adequate $\mathrm{N}$ from current-season uptake may have a continual process of leaf $\mathrm{N}$ resorption and cycling from leaves of fruiting shoots to developing fruit and seeds similar to that described for some other fruit and nut tree species. For example, using isotopically labeled $\mathrm{N}$, Weinbaum and Muraoka (1986) showed that influx of $\mathrm{N}$ into almond [Prunus dulcis (Mill.) D.A. Webb] leaves from soil uptake allowed leaf N content per unit leaf area to remain constant through the kernel fill stage, whereas leaf tissue $\mathrm{N}$ from fruiting spur shoots supplied $\mathrm{N}$ to the growing seed. Also, in english walnut (Juglans regia L.), the amount of $\mathrm{N}$ remobilized from leaves of fruiting spurs during kernel fill was 2- to 4-fold greater than that for de-fruited spurs, suggesting that protein hydrolysis in the leaves of fruiting spurs
Table 1. Probability summary from analysis of variance for leaflet nitrogen $(\mathrm{N})$ concentration data by sampling date in 2009 and $2010 .^{\mathrm{z}}$

\begin{tabular}{lccc}
\hline & \multicolumn{3}{c}{$P$ value } \\
\cline { 2 - 4 } Effect & Oct. 2009 & Oct. 2010 & Nov. 2010 \\
\hline Tree N status & 0.0006 & 0.0002 & 0.0002 \\
Shoot fruiting status & 0.0494 & 0.0007 & 0.0046 \\
N status $\times$ fruiting status & 0.3213 & 0.5485 & 0.6063
\end{tabular}

${ }^{\mathrm{z}}$ Leaflets were sampled from fruiting and non-fruiting shoots on mature 'Western' pecan trees in three tree N status categories. The study was conducted at Las Cruces, NM. Statistical significance was defined in this study as $P \leq 0.05$.

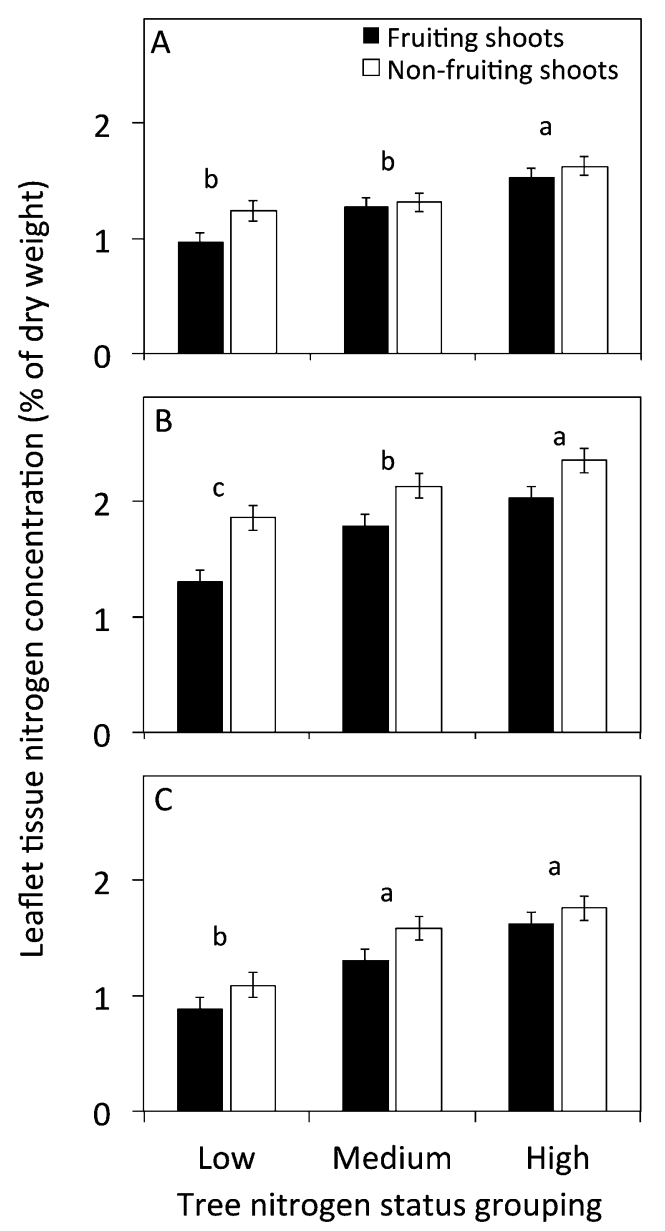

Fig. 1. Tissue nitrogen $(\mathrm{N})$ concentration by dry weight of leaflets sampled from fruiting and non-fruiting shoots on low, medium, and high $\mathrm{N}$ status pecan trees. Tree $\mathrm{N}$ status groupings were initially delineated using leaf SPAD readings and the groupings received differential soil $\mathrm{N}$ application rates in 2009 and 2010. Leaflets were sampled on 2 Oct. 2009 (A), 1 Oct. 2010 (B), and 5 Nov. 2010 (C). Data are least squares means (weighted means) \pm modelbased SE. For a given date, tree $\mathrm{N}$ status groupings (across shoot fruiting status) accompanied by the same lower-case letter not are significantly different at $P \leq 0.05$.

was supplying kernel $\mathrm{N}$ demands (Weinbaum et al., 1994). Under low N supply, like in our study, $\mathrm{N}$ transport into leaves from uptake may be insufficient to balance export of $\mathrm{N}$ from hydrolyzed leaf proteins so that total leaf $\mathrm{N}$ declines on fruiting shoots during periods of high fruit $\mathrm{N}$ demand. Moreover, although we did not measure protein hydrolysis in our study, 
it is possible that leaf protein hydrolysis and $\mathrm{N}$ remobilization are initiated earlier and at accelerated rates with decreasing $\mathrm{N}$ availability (as has been demonstrated to occur in annual plants; Aguera et al., 2010; Lers, 2007; Thomas and deVilliers, 1996), which would serve to further compound differences in leaf $\mathrm{N}$ between $\mathrm{N}$-deficient and $\mathrm{N}$-sufficient trees.

Table 2. Probability summary from analysis of variance for leaf photosynthesis data by measurement date in 2009 and $2010 .^{\mathrm{z}}$

\begin{tabular}{lccc}
\hline & \multicolumn{3}{c}{$P$ value } \\
\cline { 2 - 4 } Effect & Oct. 2009 & Oct. 2010 & Nov. 2010 \\
\hline Tree N status & 0.0003 & 0.0084 & 0.0042 \\
Shoot fruiting status & 0.0135 & $<0.0001$ & 0.0041 \\
N status $\times$ fruiting status & 0.3580 & 0.1072 & 0.9720
\end{tabular}

zPhotosynthesis measurements were made on leaves of fruiting and non-fruiting shoots on mature 'Western' pecan trees of varying nitrogen (N) nutritional status. The study was conducted at Las Cruces, NM. Statistical significance was defined in this study as $P \leq$ 0.05 .

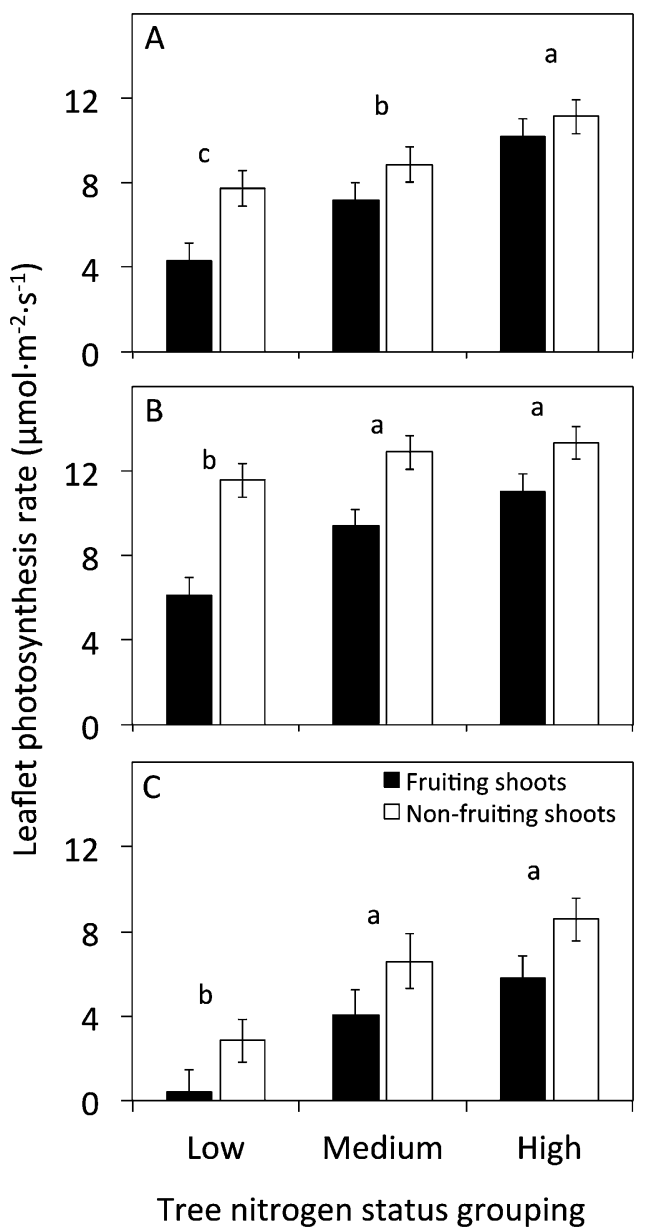

Fig. 2. Photosynthetic rate of leaflets from fruiting and non-fruiting shoots on low, medium, and high nitrogen $(\mathrm{N})$ status pecan trees. Tree $\mathrm{N}$ status groupings were initially delineated using leaf SPAD readings and the groupings received differential soil $\mathrm{N}$ application rates in 2009 and 2010 . Dates of measurement were 2 Oct. 2009 (A), 1 Oct. 2010 (B), and 5 Nov. 2010 (C). Data are least squares means (weighted means) \pm model-based SE. For a given date, tree $\mathrm{N}$ status groupings (across shoot fruiting status) accompanied by the same lower-case letter are not significantly different at $P \leq 0.05$.
For $\mathrm{P}_{\mathrm{n}}$, there were also significant tree $\mathrm{N}$ status and shoot fruiting status relationships and the two-way interaction of these was again not significant (Table 2). Like with leaf $\mathrm{N}$ concentration, the impacts of tree $\mathrm{N}$ status and shoot fruiting status on $\mathrm{P}_{\mathrm{n}}$ were additive such that photosynthetic rate of leaves from fruiting shoots was negatively impacted relatively more than that from non-fruiting shoots (Fig. 2). This was especially dramatic in Nov. 2010 (at the end of kernel filling) when, comparing low $\mathrm{N}$ and high $\mathrm{N}$ trees, there was a $66.7 \%$ reduction in photosynthetic rate for leaves on non-fruiting shoots and a $92.5 \%$ reduction for leaves of fruiting shoots. Photosynthesis for both fruiting and non-fruiting shoots increased curvilinearly with increasing $\mathrm{N}$ concentration throughout the range of leaf $\mathrm{N}$ concentration in this study $[0.69 \%$ to $2.70 \%$ (Fig. 3)]. Our model predicts that $\mathrm{P}_{\mathrm{n}}$ during kernel fill will be $97 \%$ saturated at $2.7 \%$ leaf $\mathrm{N}$ (the highest leaf $\mathrm{N}$ concentration in the study) during kernel fill stage and that $P_{n}$ would reach full saturation at $3.1 \%$ leaf $\mathrm{N}$.

Our data showing a negative shoot-level impact of fruiting on $\mathrm{P}_{\mathrm{n}}$ contrast with results from other studies in pecan demonstrating local enhancement of $P_{n}$ by the presence of developing fruit. For trees with presumably adequate $\mathrm{N}$ nutrition, two studies have shown leaf photosynthetic rates on fruiting pecan shoots were increased by $10 \%$ or more compared with leaves on non-fruiting shoots (Mielke, 1981; Wood, 1988). A third study showed no difference in $\mathrm{P}_{\mathrm{n}}$ rates between leaves on fruiting and non-fruiting 'Western' pecan shoots in September if the bark of both shoot types was left intact (ungirdled), but there was a 10-fold increase in $\mathrm{P}_{\mathrm{n}}$ rates for leaves on fruiting shoots compared with leaves on non-fruiting shoots when both shoot types were girdled, severing the phloem connection to the rest of the tree (Marquard, 1987). Increased carbon sink demand by fruit relative to leaf area is usually associated with elevated carbon assimilation rates in fruit trees (BenMimoun et al., 1996; Flore and Lakso, 1989; Palmer et al., 1997; Syvertsen et al., 2003). However, as is emphasized in a review by Paul and Foyer (2001), the interaction of carbohydrates and $\mathrm{N}$ levels can be the most influential factor in

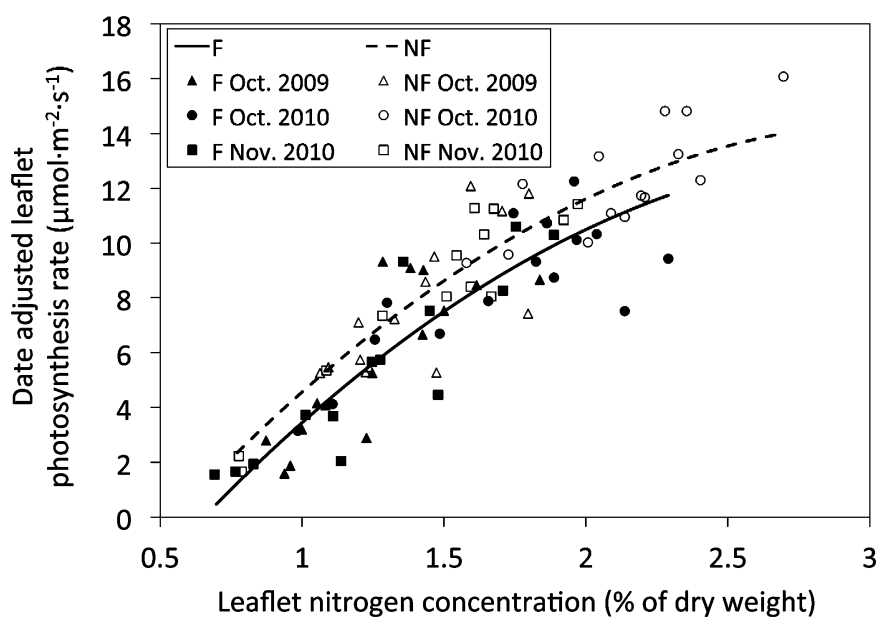

Fig. 3. The relationship of photosynthesis rate of leaflets on fruiting (F) and nonfruiting (NF) pecan shoots to nitrogen concentration by dry weight in that leaflet. Each photosynthesis data point was adjusted by measurement date as follows: Oct. 2009, -1.59 ; Oct. 2010, -0.49 ; Nov. 2010, +2.08. The data were fitted to the quadratic polynomial equation $\mathrm{y}=-2.13 \mathrm{x}^{2}+13.43 \mathrm{x}$ with $y$-intercepts -6.74 and -7.86 for non-fruiting and fruiting shoots, respectively. 
regulating photosynthetic rates. As $\mathrm{N}$ supply becomes increasingly restricted for plants that have periods of intense fruit $\mathrm{N}$ demand (e.g., pecan kernel fill), $\mathrm{N}$ remobilization from Rubisco (and possibly other N-containing components of the photosynthetic apparatus) could reach a point at which the normal relationship of fruit carbon demands and elevated $P_{n}$ disappears or is reversed, as we observed.

For PNUE, the tree $\mathrm{N}$ status main effect was significant only on the Nov. 2010 sampling date and the two-way $\mathrm{N}$ status by fruiting status interaction was not significant on any of the three sampling dates (Table 3). In 2010, the shoot fruiting status main effect for PNUE was significant on both the October and November sampling dates (Table 3). In Nov. 2010, mean PNUE of leaves on fruiting and non-fruiting shoots were 3.3 and

Table 3. Probability summary from analysis of variance for leaflet photosynthetic nitrogen $(\mathrm{N})$ use efficiency data from 'Western' pecan trees by measurement date in 2009 and $2010 .^{z}$

\begin{tabular}{lccc}
\hline & \multicolumn{3}{c}{$P$ value } \\
\cline { 2 - 4 } Effect & Oct. 2009 & Oct. 2010 & Nov. 2010 \\
\hline Tree N status & 0.1702 & 0.6318 & 0.0464 \\
Shoot fruiting status & 0.0856 & $0.0440^{\mathrm{y}}$ & 0.0108 \\
N status $\times$ fruiting status & 0.1677 & 0.2853 & 0.6319 \\
\hline
\end{tabular}

${ }^{\mathrm{z}}$ Measurements were made on leaflets from fruiting and non-fruiting shoots on trees of varying $\mathrm{N}$ nutritional status. The study was conducted at Las Cruces, NM. Statistical significance was defined in this study as $P \leq 0.05$.

${ }^{\mathrm{y}}$ Removal of a single outlier results in a $P$ value of 0.1224 .

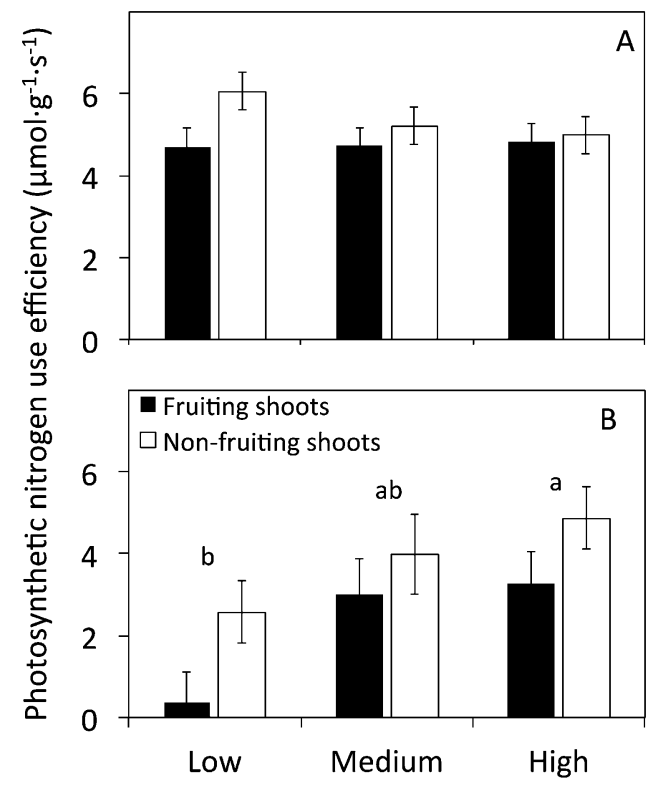

Tree nitrogen status grouping

Fig. 4. Photosynthetic nitrogen $(\mathrm{N})$ use efficiency of leaflets from fruiting and non-fruiting shoots on low, medium, and high $\mathrm{N}$ status pecan trees. Tree $\mathrm{N}$ status groupings were initially delineated using leaf SPAD readings and the groupings received differential soil N application rates in 2009 and 2010. Measurements were made on three dates, but only data from the two dates where at least one of the main effects were statistically significant $(P \leq 0.05)$, 1 Oct. 2010 (A) and 5 Nov. 2010 (B), are presented. Data are least squares means (weighted means) \pm model-based SE. For a given date, tree $\mathrm{N}$ status groupings (across shoot fruiting status) accompanied by the same lower-case letter are not significantly different at $P \leq 0.05$.
$4.9 \mu \mathrm{mol} \cdot \mathrm{g}^{-1} \cdot \mathrm{s}^{-1}$, respectively, for high $\mathrm{N}$ status trees and 0.4 and $2.6 \mu \mathrm{mol} \cdot \mathrm{g}^{-1} \cdot \mathrm{s}^{-1}$ for low $\mathrm{N}$ trees (Fig. 4). Comparing high and low $\mathrm{N}$ status trees, that is a $87.9 \%$ reduction in PNUE for fruiting shoots and a $46.9 \%$ reduction in PNUE for non-fruiting shoots. Thus, in November, $\mathrm{P}_{\mathrm{n}}$ of low $\mathrm{N}$ leaves, especially on fruiting shoots, had been impacted by $\mathrm{N}$ deficiency to a far

Table 4. Probability summary from analysis of variance for leaflet intercellular $\mathrm{CO}_{2}$ concentration data by measurement date in 2009 and $2010 .^{\mathrm{z}}$

\begin{tabular}{lrcc}
\hline & \multicolumn{3}{c}{$P$ value } \\
\cline { 2 - 4 } Effect & Oct. 2009 & Oct. 2010 & Nov. 2010 \\
\hline Tree N status & 0.0210 & 0.0179 & 0.0052 \\
Shoot fruiting status & $<0.0001$ & 0.7708 & 0.1422 \\
N status $\times$ fruiting status & 0.7852 & 0.1510 & 0.1010
\end{tabular}

${ }^{\mathrm{z}}$ Measurements were made on leaves of fruiting and non-fruiting shoots on mature 'Western' pecan trees of varying nitrogen $(\mathrm{N})$ nutritional status. The study was conducted at Las Cruces, NM. Statistical significance was defined in this study as $P \leq 0.05$.

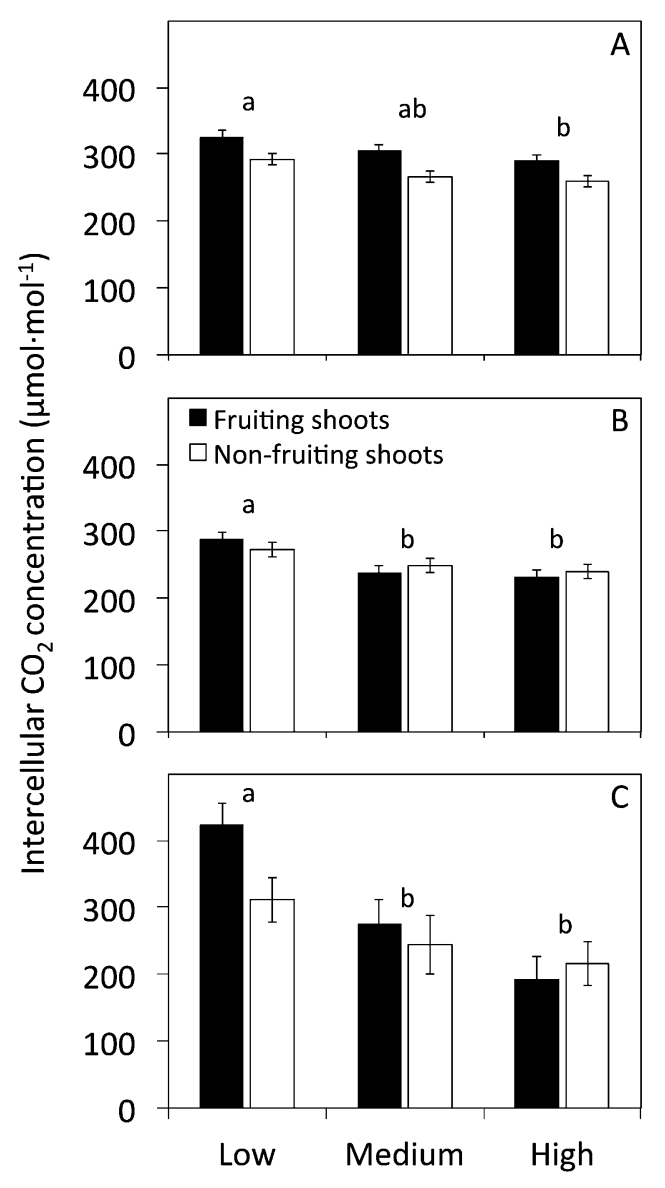

Tree nitrogen status grouping

Fig. 5. Intercellular $\mathrm{CO}_{2}$ concentration of leaflets from fruiting and non-fruiting shoots on low, medium, and high nitrogen $(\mathrm{N})$ status pecan trees. Tree $\mathrm{N}$ status groupings were initially delineated using leaf SPAD readings and the groupings received differential soil $\mathrm{N}$ application rates in 2009 and 2010. Dates of measurement were 2 Oct. 2009 (A), 1 Oct. 2010 (B), and 5 Nov. 2010 (C). Data are least squares means (weighted means) \pm model-based SE. For a given date, tree $\mathrm{N}$ status groupings (across shoot fruiting status) accompanied by the same lower-case letter are not significantly different at $P \leq 0.05$. 
greater extent than leaf $\mathrm{N}$ content, indicating that photosynthetic $\mathrm{N}$ in November made up a proportionally much smaller part of the total remaining $\mathrm{N}$ in the leaf of low $\mathrm{N}$ trees compared with high $\mathrm{N}$ status trees.

Intercellular $\mathrm{CO}_{2}$ was reduced by increasing tree $\mathrm{N}$ status on all three sampling dates (Table 4; Fig. 5), but stomatal conductance $\left(g_{\mathrm{S}}\right)$ was not significantly related to tree $\mathrm{N}$ status (Table 5; Fig. 6). These results indicate that maximum $\mathrm{P}_{\mathrm{n}}$ rate on low $\mathrm{N}$ status trees was determined by nonstomatal limitations: either reduced carboxylation capacity or insufficient RuBP from the Calvin cycle to supply higher carboxylation rates. On the other hand, the mechanism for localized reductions in $\mathrm{P}_{\mathrm{n}}$ by fruiting was less clear. The main fruiting effect for intercellular $\mathrm{CO}_{2}$ was significant only on the Oct. 2009 sampling date (Table 4 ), whereas $g_{S}$ was significantly lower for fruiting shoots only on the two 2010 sampling dates (Table 5; Fig. 6). Our 2010 conductance results are opposite other studies, which have shown positive relationships between leaf $g_{\mathrm{S}}$ and cropload (at the shoot or whole tree level) in 'Desirable' pecan (Wood, 1988) and other fruit trees (DeJong, 1986;

Table 5. Probability summary from analysis of variance for leaflet stomatal conductance data by measurement date in 2009 and $2010{ }^{z}$

\begin{tabular}{lccc}
\hline & \multicolumn{3}{c}{$P$ value } \\
\cline { 2 - 4 } Effect & Oct. 2009 & Oct. 2010 & Nov. 2010 \\
\hline Tree N status & 0.0787 & 0.6467 & 0.0680 \\
Shoot fruiting status & 0.5926 & 0.0007 & 0.0034 \\
N status $\times$ fruiting status & 0.1620 & 0.5417 & 0.4240
\end{tabular}

${ }^{\mathrm{z}}$ Measurements were made on leaves of fruiting and non-fruiting shoots on mature 'Western' pecan trees of varying nitrogen $(\mathrm{N})$ nutritional status. The study was conducted at Las Cruces, NM. Statistical significance was defined in this study as $P \leq 0.05$.

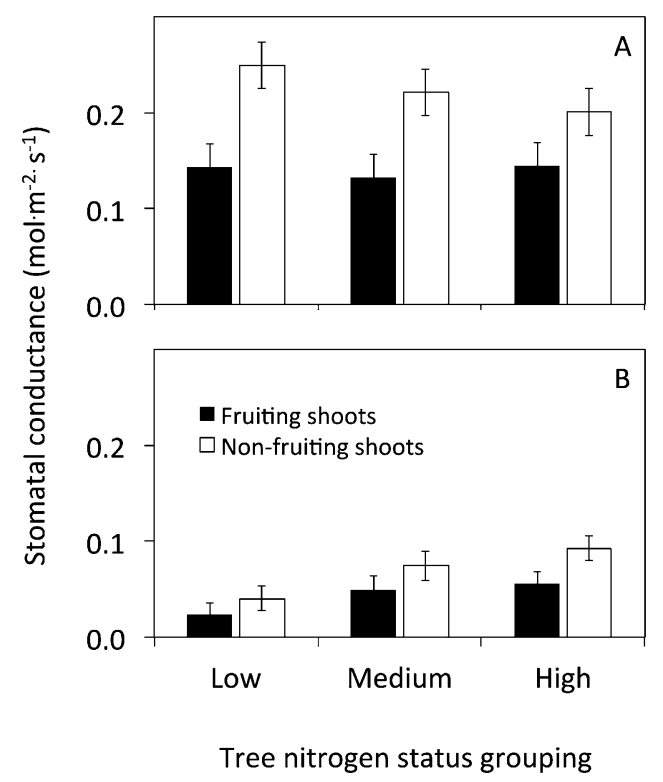

Fig. 6. Stomatal conductance $\left(g_{\mathrm{S}}\right)$ to water vapor of leaflets from fruiting and non-fruiting shoots on low, medium, and high nitrogen $(\mathrm{N})$ status pecan trees. Tree N status groupings were initially delineated using leaf SPAD readings and the groupings received differential soil $\mathrm{N}$ application rates in 2009 and 2010. Measurements were made on three dates, but only data from the two dates where the shoot fruiting status main effect were statistically significant $(P \leq 0.05), 1$ Oct. 2010 (A) and 5 Nov. 2010 (B), are presented. Data are least squares means (weighted means) \pm model-based SE.
Syvertsen et al., 2003) where $\mathrm{N}$ was presumably in adequate supply (unlike our study where nearly all of the trees were $\mathrm{N}$-deficient both years).

We conclude that for $\mathrm{N}$-deficient pecan trees, local impacts of kernel $\mathrm{N}$ demands outweigh the photosynthetic enhancement effect that fruit may have on leaves of trees that are N-sufficient. Kernel fill is a period of rapid fruit accumulation of $\mathrm{N}$ and heavy fruit photosynthate demand to satisfy rapid lipid biosynthesis in the kernel. Diminished photosynthetic output on fruiting pecan shoots and locally limited carbohydrate supplies in the latter part of the growing season (especially in heavy cropload seasons when there may be few non-fruiting shoots) is therefore expected to directly negatively impact current-season kernel growth in N-deficient orchards. This would be realized by pecan producers at harvest as reductions in total nut yield (weight) per tree, average nut size, and percentage kernel, which are among the most important determinants of profitability in pecan production. Development of a technique for monitoring changes in leaf $\mathrm{N}$ concentration (or tracking leaf SPAD readings) on fruiting shoots in the early stages of kernel fill could potentially prove useful, alongside regular annual tissue nutrient analyses from July-sampled leaves, for making late-season $\mathrm{N}$ fertilizer application decisions in pecan orchards.

\section{Literature Cited}

Acuña-Maldonado, L.E., M.W. Smith, N.O. Maness, B.S. Cheary, B.L. Carroll, and G.V. Johnson. 2003. Influence of nitrogen application time on nitrogen absorption, partitioning, and yield of pecan. J. Amer. Soc. Hort. Sci. 128:155-162.

Aguera, E., P. Cabello, and P. de la Haba. 2010. Induction of leaf senescence by low nitrogen nutrition in sunflower (Helianthus annuus) plants. Physiol. Plant. 138:256-267.

Alexander, P.J., G. Rajanikanth, C. Bacon, and D. Bailey. 2006. Recovery of plant DNA using a reciprocating saw and silica-based columns. Mol. Ecol. Notes 7:5-9.

Anderson, P.C. 1994. Temperate nut species, p. 299-338. In: Schaffer, B. and P.C. Anderson (eds.). Handbook of environmental physiology of fruit crops. Vol. I: Temperate crops. CRC Press, New York, NY. Barker, A.V. and G.M. Bryson. 2007. Nitrogen, p. 21-50. In: Barker, A.V. and D.J. Pilbeam (eds.). Handbook of plant nutrition. CRC Press, New York, NY.

BenMimoun, M., J.J. Longuenesse, and M. Genard. 1996. Pmax as related to leaf: Fruit ratio and fruit assimilate demand in peach. J. Hort. Sci. 71:767-775.

DeJong, T.M. 1986. Fruit effects on photosynthesis in Prunus persica. Physiol. Plant. 66:149-153.

Diver, S.G., M.W. Smith, and R.W. McNew. 1984. Influence of fruitdevelopment on seasonal elemental concentrations and distribution in fruit and leaves of pecan. Commun. Soil Sci. Plant Anal. 15:619-637.

Evans, J.R. 1989. Photosynthesis and nitrogen relationships in leaves of C-3 plants. Oecologia 78:9-19.

Evans, J.R. and I. Terashima. 1987. Effects of nitrogen nutrition on electron transport components and photosynthesis in spinach. Aust. J. Plant Physiol. 14:59-68.

Flore, J.A. and A.N. Lakso. 1989. Environmental and physiological regulation of photosynthesis in fruit crops. Hort. Rev. 11:111-150.

Gavlak, R.G., D.A. Horneck, and R.O. Miller. 1994. Soil and plant tissue reference methods for the western region. Western Reg. Ext. Publ. 125.

Hammar, H.E. and J.H. Hunter. 1946. Some physical and chemical changes in the composition of pecan nuts during kernel filling. Plant Physiol. 21:476-491.

Heerema, R. 2013. Diagnosing nutrient disorders of New Mexico pecan trees. New Mexico State Univ. Coop. Ext. Guide H-658. 9 Dec. 2013. $<$ http://aces.nmsu.edu/pubs/_h/H658.pdf>. 
Heerema, R.J., S.A. Weinbaum, B.D. Lampinen, and T.M. DeJong. 2009. Is nitrogen stress more apparent in shaded, fruiting almond spurs than in exposed, non-fruiting spurs? J. Hort. Sci. Biotechnol. $84: 355-359$.

Herrera, E.A. 1990. Fruit growth and development of 'Ideal' and 'Western' pecans. J. Amer. Soc. Hort. Sci. 115:915-923.

Klein, I., S.A. Weinbaum, T.M. DeJong, and T.T. Muraoka. 1991. Relationship between fruiting, specific leaf weight, and subsequent spur productivity in walnut. J. Amer. Soc. Hort. Sci. 116:426-429.

Kozlowski, T.T. and S.G. Pallardy. 1997. Physiology of woody plants. Academic Press, New York, NY.

Kraimer, R.A., W.C. Lindemann, and E.A. Herrera. 2001. Distribution of ${ }^{15} \mathrm{~N}$-labeled fertilizer applied to pecan: A case study. HortScience 36:308-312.

Lers, A. 2007. Environmental regulation of leaf senescence, p. 108144. In: Gan, S. (ed.). Senescence processes in plants. Blackwell Publishing, Ames, IA.

Lewis, R.D. and J.H. Hunter. 1944. Changes in some mineral constituents of pecan nuts and their supporting shoots during development. J. Agr. Res. 68:299-306.

Marquard, R.D. 1987. Influence of leaf to fruit ratio on nut quality, shoot carbohydrates, and photosynthesis of pecan. HortScience 22:256-257.

Mielke, E.A. 1981. Effect of stress on pecan photosynthesis. Proc. Western Pecan Growers Assn. Conf. 15:47-65.

Natr, L. 1975. Influence of mineral nutrition on photosynthesis and the use of assimilates, p. 537-555. In: Cooper, J.P. (ed.). Photosynthesis and productivity in different environments. Cambridge University Press, Cambridge, UK.

New Mexico State University. 2013. SWAT Lab References for Plant Analyses, Las Cruces, NM. 8 May 2013. <http://aces.nmsu.edu/aes/ plantanalysis.html>.

Palmer, J.W., R. Giuliani, and H.M. Adams. 1997. Effect of crop load on fruiting and leaf photosynthesis of 'Braeburn'/M.26 apple trees. Tree Physiol. 17:741-746.

Paul, M.J. and C.H. Foyer. 2001. Sink regulation of photosynthesis. J. Expt. Bot. 52:1383-1400.

Ramsey, F.L. and D.W. Schafer. 2002. The statistical sleuth: A course in methods of data analysis. Brooks/Cole Cengage, Boston, MA.

Sesay, A. and R. Shibles. 1980. Mineral depletion and leaf senescence in soya bean as influenced by foliar nutrient application during seed filling. Ann. Bot. (Lond.) 45:47-55.

Shackel, K.A., H. Ahmadi, W. Biasi, R. Buchner, D. Goldhamer, S. Gurusinghe, J. Hasey, D. Kester, B. Krueger, B. Lampinen, G.
McGourty, W. Micke, E. Mitcham, B. Olson, K. Pelletrau, H. Philips, D. Ramos, L. Schwankl, S. Sibbett, R. Snyder, S. Southwick, M. Stevenson, M. Thorpe, S. Weinbaum, and J. Yeager. 1997. Plant water status as an index of irrigation need in deciduous fruit trees. HortTechnology 7:23-29.

Simpson, R.J., H. Lambers, and M.J. Dalling. 1983. Nitrogen redistribution during grain growth in wheat (Triticum aestivum L). IV. Development of a quantitative model of the translocation of nitrogen to the grain. Plant Physiol. 71:7-14.

Singanusong, R., R.L. Mason, B.R. D'arcy, and S.M. Nottingham. 2003. Compositional changes of Australia-grown Western Schley pecans [Carya illinoinensis (Wangenh.) K. Koch] during maturation. J. Agr. Food Chem. 51:406-412.

Sparks, D. 1977. Effects of fruiting on scorch, premature defoliation, and nutrient status of 'Chickasaw' pecan leaves. J. Amer. Soc. Hort. Sci. 102:669-673.

St. Hilaire, R. and Y. Othman. 2013. Photosynthesis and gas exchange are maintained during multiple cycles of moderate drought stress of pecan. Plant Biol. 2013 Poster P1 1007 (Abstr.). 9 Dec. 2013. <http:// c.ymcdn.com/sites/my.aspb.org/resource/resmgr/rhodeisland2013/ plantbiology2013_abstracts.pdf $>$.

Syvertsen, J.P., C. Goni, and A. Otero. 2003. Fruit load and canopy shading affect leaf characteristics and net gas exchange of 'Spring' navel orange trees. Tree Physiol. 23:899-906.

Thomas, H. and L. deVilliers. 1996. Gene expression in leaves of Arabidopsis thaliana induced to senesce by nutrient deprivation. J. Expt. Bot. 47:1845-1852.

Thor, C.J.B. and C.L. Smith. 1935. A physiological study of seasonal changes in the composition of the pecan during fruit development. J. Agr. Res. 50:97-121.

U.S. Department of Agriculture. 2013. Natural Resources Conservation Service web soil survey. 19 Aug. 2013. <http://websoilsurvey. sc.egov.usda.gov/App/WebSoilSurvey.aspx>.

Weinbaum, S.A. and T.T. Muraoka. 1986. Nitrogen redistribution from almond foliage and pericarp to the almond embryo. J. Amer. Soc. Hort. Sci. 111:224-228.

Weinbaum, S.A., T.T. Muraoka, and R.E. Plant. 1994. Intracanopy variation in nitrogen cycling through leaves is influenced by irradiance and proximity to developing fruit in mature walnut trees. Trees Structure Function 9:6-11.

Wood, B.W. 1988. Fruiting affects photosynthesis and senescence of pecan leaves. J. Amer. Soc. Hort. Sci. 113:432-436.

Wood, B.W. and C.C. Reilly. 1984. Pecan kernel proteins and their changes with kernel development. HortScience 19:661-663. 